\title{
Editorial to the special issue on CMBEBIH 2019: biomedical engineering - share the vision
}

\author{
Almir Badnjević ${ }^{1}$ \\ Published online: 11 January 2020 \\ (C) IUPESM and Springer-Verlag GmbH Germany, part of Springer Nature 2020
}

It is our pleasure to present this special issue which contains a collection of 13 papers. Some of the papers are extended papers from the International Conference on Medical and Biological Engineering (CMBEBIH 2019), and the other ones are journal style papers within the scope of CMBEBIH topics. CMBEBIH is a biannual international conference organized by Bosnia and Herzegovina Medical and Biological Engineering Society. IFMBE, ESEM, and IEEE are endorsed conferences which tackle the trending topics in the field of biomedical engineering. The 2019 edition of the conference was held in Banja Luka, Bosnia, and Herzegovina and attracted a total of 116 regular paper submissions, spanning over 10 different topic areas.

Biomedical engineering is an application of traditional engineering principles and design procedures to analyze and solve problems in biology and medicine. This field seeks to close the gap between engineering and medicine, combining the design and problem-solving skills of engineering with medical biological sciences to advance healthcare treatment, including diagnosis, monitoring, and therapy. Also included under the scope of a biomedical engineering is the management of current medical equipment within hospitals while adhering to relevant industry standards. Prominent biomedical engineering applications include the development of biocompatible prostheses, various diagnostic and therapeutic medical devices ranging from clinical equipment to micro-implants, common imaging equipment such as MRIs and EKG/ECGs, regenerative tissue growth, pharmaceutical drugs, and therapeutic biologicals.

The 13 extended papers for this special issue were selected from the papers submitted by the authors and by the special

Almir Badnjević

badnjevic.almir@gmail.com

1 Medical Device Inspection Laboratory Verlab, Verlab, Sarajevo, Bosnia and Herzegovina issue guest editors, Prof. Dr. Almir Badnjević and Prof. Dr. Ranko Škrbić, based on the relevance to the journal and the reviews of the conference version of the papers, as well as journal-style review of the submitted extended versions of the papers. The revised papers are finally presented to the readers in the present form. We appreciate the willingness of the authors to help in organizing this special issue.

The papers published within this special issue present the work of Kovacevic et al. [1] about the new approach in predictive maintenance of medical devices using machine learning algorithms, as well as health and safety model for occupational exposure to radio-frequency fields and static magnetic fields by Rathebe et al. [2]. Readers interested in e-healthcare field can find two interesting topics presented by Iadanza et al. $[3,4]$. One is about the custom decision-support computeraided facility management informative system [3], and the other one is about collaborative RESTful cloud-based tool for management of chromatic pupillometry in a clinical trial [4]. Field of nanotechnology is addressed by three papers [5-7]. Omanovic-Miklicanin et al. [5] give an overview of nanocomposites, Kazlagic et al. present green synthesis of silver nanoparticles using apple extract and its antimicrobial properties [6], and Vranic et al. [7] present the results of application of nanoparticles in ocular drug delivery systems. Analysis of biomedical signals is always a tending field in biomedical engineering. In this special issue, assessing autonomic control of metabolic diseases by principal component analysis is presented by Pinto et al. [8], as well as results of audiovisual stimulation-based emotion classification by correlated EEG channels by Ahirwal et al. [9]. This special editorial presents the topic of genetic and pharmaceutical engineering as well. The readers can find interesting the topics of mechanical impact stimulation platform tailored for high-resolution light microscopy by Halonen et al. [10]. A comprehensive review of the multidisciplinary in karyotypization by Dzanko et al. [11] along with screening of antioxidant and cytotoxic activities of several microalgal extracts with pharmaceutical potential by Gurlek et al. [12] is presented as well. 
Finally, editors chose to present an interesting approach in modeling and reference tracking of the robotic above-knee prosthetic leg with actuated knee and ankle joints during stair climbing by authors Jelacic and Dedic [13].

Finally, we hope that readers will find this special issue useful for continuous research and that they will join the CMBEBIH community in sharing the vision of prosperous collaborations within the biomedical engineering filed.

\section{References}

1. Kovačević Ž, Gurbeta Pokvić L (2019) Spahić. L et al Health Technol:1-5. https://doi.org/10.1007/s12553-019-00386-5

2. Rathebe P, Weyers C, Raphela F (2019) A health and safety model for occupational exposure to radiofrequency fields and static magnetic fields from 1.5 and 3 T MRI scanners. In: Health Technol. https://doi.org/10.1007/s12553-019-00379-4

3. Iadanza E, Luschi A (2019) An integrated custom decision-support computer aided facility management informative system for healthcare facilities and analysis. In: Health Technol. https://doi. org/10.1007/s12553-019-00377-6

4. Iadanza E, Fabbri R (2019) Luschi. A. et al. Health Technol.:1-14. https://doi.org/10.1007/s12553-019-00362-z

5. Omanović-Mikličanin E, Badnjević A (2019) Kazlagić. A et al Health Technol:1-9. https://doi.org/10.1007/s12553-019-00380-x

6. Kazlagić A, Abud OA, Ćibo M et al (2019) Green synthesis of silver nanoparticles using apple extract and its antimicrobial properties. In: Health Technol. https://doi.org/10.1007/s12553019-00378-5

7. Omerović N, Vranić E (2019) Application of nanoparticles in ocular drug delivery systems. In: Health Technol. https://doi.org/10. 1007/s12553-019-00381-w

8. Fonseca-Pinto R, Lopes NV, Brito GC et al (2019) Assessing autonomic control of metabolic syndrome by principal component analysis: a data driven methodology. In: Health Technol. https://doi.org/ 10.1007/s12553-019-00384-7

9. Ahirwal MK, Kose MR (2019) Health Technol. https://doi.org/10. 1007/s12553-019-00394-5

10. Halonen HT, Hyttinen JA, Ihalainen TO (2019) Mechanical impact stimulation platform tailored for high-resolution light microscopy. In: Health Technol. https://doi.org/10.1007/s12553-019-00382-9

11. Džanko A, El Sayed A, Međedović S (2019) A comprehensive review of the Multidisciplinarity in Karyotypization. In: Health Technol. https://doi.org/10.1007/s12553-019-00389-2

12. Gürlek C, Yarkent C, Köse A et al (2019) Screening of antioxidant and cytotoxic activities of several microalgal extracts with pharmaceutical potential. In: Health Technol. https://doi.org/10.1007/ s12553-019-00388-3

13. Jelačić Z, Dedić R (2019) Modelling and reference tracking of the robotic above-knee prosthetic leg with actuated knee and ankle joints during stair climbing. In: Health Technol. https://doi.org/10. 1007/s12553-019-00383-8

Publisher's note Springer Nature remains neutral with regard to jurisdictional claims in published maps and institutional affiliations. 